\title{
A new species of Hexabdella (Acari: Bdellidae) from Brazil
}

\author{
FÁBIO A. HERNANDES ${ }^{1}$, RODRIGO D. DAUD ${ }^{1} \&$ REINALDO J.F. FERES ${ }^{2}$ \\ ${ }^{1} P P G$ Biologia Animal, UNESP - São José do Rio Preto, São Paulo, Brazil; \\ E-mail:fabio_akashi@yahoo.com.br,rodrigodaud@yahoo.com.br \\ ${ }^{2}$ UNESP - São Paulo State University -Instituto de Biociências, Letras e Ciências Exatas; Rua Cristóvão Colombo, 2265, Jardim Naz- \\ areth, São José do Rio Preto, São Paulo, Brazil. 15054-000; Depto. Zoologia e Botanica. E-mail: reinaldo@ibilce.unesp.br
}

\begin{abstract}
A new species of the genus Hexabdella Van der Schyff, Theron \& Ueckermann, Hexabdella cinquaginta sp.n. is herein described, representing the second species of the family Bdellidae from the neotropical region. It can be distinguished from $H$. singula by its lobed striae on lateral margins of hysterosoma and by the leg chaetotaxy. A key to species of the genus is presented.
\end{abstract}

Key words: Acari, Prostigmata, Bdellidae, Systematics

\section{Introduction}

Mites of the family Bdellidae are predators of insects and mites (Gerson et al. 2003, Atyeo 1960), known to occur on all continents (Atyeo 1960; Atyeo \& Luxen 1962; Swift \& Goff 1987; Wallace \& Mahon 1972; Tseng 1978; Hernandes \& Feres 2006). They have been collected in Brazil mainly in the State of São Paulo, on rubber tree crops (Feres et al. 2002; Bellini et al. 2005; Demite \& Feres 2005; Hernandes \& Feres 2006a, 2006b, Vis et al. 2006), Coffea arabica (Mineiro et al. 2006) and Mabea fistulifera leaves of forest patches (Daud \& Feres 2005).

Van der Schyff et al. (2004) erected the genus Hexabdella to accommodate five new species from Angola and South Africa. They also transferred H. mexicana (Baker \& Balock) from the genus Bdella to Hexabdella, found in Mexico and Hawaii (Swift \& Goff 1987). The main diagnostic character of this genus is the presence of six trichobothriae, on tibiae I, IV and on tarsi III. Recently, Hernandes \& Feres (2006) described the first bdellid species, Tetrabdella neotropica, from the Neotropical region. In this paper we describe a second species from Brazil, of the genus Hexabdella.

\section{Materials and methods}

Mites were sampled from rubber tree leaflets, Hevea brasiliensis, from Itiquira, state of Mato Grosso, and from twigs of Tibouchina sp., from Serra do Japi, state of São Paulo, Brazil. The mites were mounted on microscopy slides using Hoyer's medium. Measurements and drawings were made under phase contrast microscopy and the values are given in micrometers $(\mu \mathrm{m})$. The body length of all specimens was measured from the apex of hypostome to posterior margin of idiosoma, and body width at the level of setae $c 2$. Setal lengths were recorded from the setal base to tip. Legs were measured from the ventral insertion of coxae to the base of pretarsi. The setal nomenclature is according to Kethley (1990). Abbreviations of setae are as follows: Propodosomal setae: internal verticals (vi), external verticals (ve), internal scapular (sci), external scapular $(s c e)$. Opistosomal setae: internal humeral $(c 1)$, external humeral $(c 2)$, internal dorsal $(d l)$, internal lumbal 